\title{
Riparian Vegetation Management: Reconciling Environmental and Anthropogenic Issues
}

\author{
Caroline Zanetti", Nelly Liency \\ ARBEAUSOLutions, Belcodène, France \\ Email address: \\ c.zanetti@arbeausolutions.fr (C. Zanetti) \\ ${ }^{*}$ Corresponding author
}

To cite this article:

Caroline Zanetti, Nelly Liency. Riparian Vegetation Management: Reconciling Environmental and Anthropogenic Issues. American Journal of Environmental Science and Engineering. Vol. 3, No. 2, 2019, pp. 31-38. doi: 10.11648/j.ajese.20190302.11

Received: July 5, 2019; Accepted: August 3, 2019; Published: August 28, 2019

\begin{abstract}
Historically, people lived in harmony with watercourses, cultivating their land and creating their habitat according to the benefits and the whims of the rivers. Since the beginning of the 20th century, man has domesticated his environment with determination. The rural exodus, the agricultural depreciation and the numerous river amenities have resulted in a momentum of area closures and in the modification of hydraulic conditions during the flow of flood waters. An unmanaged vegetation colonization along the edge of watercourses (protection dikes, retention dams, appointed river banks) induces various issues; however, a drastic management is not absolutely beneficial and sometimes even runs counter to the objective. The environmental issues conciliation - positive impact on fluvial ecosystems (shade, water decontamination, bank stabilization, biodiversity) - with anthropogenic issues is therefore essential to identify these suitable management solutions. Since 1970 and until 2006, phytopharmaceutical products were used extensively to control vegetation development on dikes, dams and canals due to their high-speed action and their low-cost implementation. Phytopharmaceutical product prohibition induces a great expansion of vegetation on structure cladding. Pioneer trees species like poplar are largely represented. Implanted near water points they grow fast in phytopharmaceutical treatment prohibited zone. Woody vegetation control methods are frequently implemented too late, when impacts caused by roots are observed; structural reparation costs are consequently very high. New vegetation management solutions have to be developed, in order to allow both risk reduction and environmental preservation. Some different eco-friendly solutions exist but must be promoted by rivers and dikes managers. This paper presents these integrated solutions and illustrates through some case studies the implemented solutions to reconcile the antagonist environmental and anthropogenic issues.
\end{abstract}

Keywords: Vegetation Management, Dikes, Risk, Environmental Preservation, Anthropogenic Issues

\section{Introduction}

For about fifty years, with the decrease of the exploitation of firewood, overgrowth of vegetation on hydraulic structures has merged with the existing riparian areas.

At the same time, civil engineering has made significant progress in the field of hydraulic structures and has resulted in the massive construction of dikes and dams. Certain populations have lost the culture of risk by feeling completely safe from floods at the back of the structures.

Hydraulic structures can take many forms, such as floodprotection dikes, canal embankments or dams. The maintenance of these structures requires certain safety principles to be respected, especially towards the excessive and sometimes harmful development of the vegetation on the structure. Although the role of structures is to ensure the safety of people and property, many canals and dikes covered with vegetation render them almost useless.

These places are gradually assimilated to biodiversity protection zones, omitting their security character. Hydrological disasters and breaks in structures are often the result of a lack of maintenance and remind of the need for control and maintenance operations. Regulation imposes a control of the vegetation by the decree of February 29th, 2008 fixing the requirements relating to the safety and the security of the hydraulic structures [1].

The upsurge of hydro-meteorological disasters over the 
past 25 years has reminded people that the hydraulic infrastructures set up over the past few centuries are not unalterable. More than $70 \%$ of hydraulic structure failures are related to premature aging leading to failure, $20 \%$ of which are attributed to deterioration factors caused by burrowing animals or woody vegetation [2].

Balance between river ecological management and flood risk control is not always easy to obtain especially when woody riparian vegetation is at stake. Sticking points often make their coexistence difficult to implement. Levees and flood control dams are obvious examples.

Ecological functions and ecosystem services provided by vegetation no longer are needed to be demonstrated

The safety element plays a significant part but the growing requirements in terms of environmental and aquatic environment conservation make the integration of ecological aspects highly recommended. The recent implementation of GEMAPI (French regulation managing aquatic environments management and flood prevention) from January 2018 recalls the need to reconcile security and environmental issues as far as possible [3]

The new "GEMAPI" legislation makes it compulsory to reconciliate management goals that may appear conflicting. The issue is the conservation of healthy functional ecosystems while guaranteeing the protection of the population and infrastructures from flooding risk.

On one side, the flood defense mission requires control and monitoring of hydraulic structures as well as a guarantee of efficiency in the protection of people and property [PI = flood risk control]. And on the other side, the mission of preservation and restoration of riparian forest formations [GEMA = river ecological management], letting nature development take its course and minimizing as far as possible human interventions, clearly goes against the mission of protection against flood as long as hydraulic structures such as dikes are built.

While the regulatory framework concerning safety and maintenance and monitoring obligations of hydraulic structures has been reinforced, the same applies for the use of phytosanitary products that are unfriendly to the environment. While this encourages managers to adopt more sustainable and environmentally responsible practices, they are faced with a complexification of vegetation management operations. It is up to the manager to define the adapted management plan [1] and [4].

The main challenge now as well as the key to river management implemented through the new GEMAPI jurisdiction is to find a compromise between drastic management of river vegetation for the purpose of protecting territories and people, and non-management or restoration of this vegetation in favor of preservation of a natural environment.

\section{The Antagonist Effects of Vegetation}

\subsection{Positive Effects of Vegetation}

The transition zone between aquatic and terrestrial environments and riparian forest is very beneficial from an environmental point of view; flora and fauna biodiversity, ecological corridor, water pollution control... From the social point of view, riparian forests protect from wind, isolate noise and by the shading it provides, users enjoy recreational areas and pleasant landscapes. Its role can be protective and stabilizing in some cases, making it possible to control bank erosion by anchoring the root systems $[5,6]$. However, this vegetation is likely to generate risks when it colonizes the surroundings of the rivers in an uncontrolled way.

\subsection{Negative Effects of Vegetation}

Uncontrolled plant colonization of riverbanks - particularly in the case of protective dikes, retention structures or developed banks - can present three types of disadvantages [1].

First of all, in watercourses invaded by vegetation, the flow velocity of floods is slowed down and the rise in water levels can locally lead to the increase of flooded areas or even to an overflow in case of containment of the watercourse;

Moreover, abundant and decaying vegetation around the watercourse encourages the formation of logjams that generate a risk of obstruction of bridges or water retention, then sudden ruptures, which can greatly increase the risk of flooding.

Finally, vegetation implanted on hydraulic structures is likely to mask disorders and generates the premature aging of embankment structures. The presence of trees and their roots thus weakens the containment systems protecting the territories.

\subsubsection{Case of Embankment Structures}

The presence of trees on the structures can cause a risk of internal and external erosion. Internal erosion is one of the main causes of failure of hydraulic earthworks. The mechanism of internal erosion is favored by the presence of the trees root system which creates an area of heterogeneity in the embankment and increases the risk of holes and galleries formation.

External erosion follows the tearing of trees (windthrow) by wind storms or by waterflow. On a dike, a tree windthrow located in an embankment punctually reduces its width creating a point of weakness. If the uprooted tree is located at the peak, the windfall creates a low point, a privileged place of overflow. If located at the foot of the dike, the consequence of external erosion may be slippage of the embankment or scouring by the swirling currents on the river / canal side.

The type of root system influences the risk of structural failure. Trees with shallow root systems are not resistant to uprooting but ensure good stabilization of the soil surface. Root systems whose structures penetrate hydraulic works (taproots) are more resistant but create destruction of materials and areas of heterogeneity that the water takes during implementation.

The materials constituting the structure play an important role in the phenomena of mechanical resistance but also influence the root development and its structure. 


\subsubsection{Case of Protective-Coatings}

When root systems develop in the structure's surface where the upstream faces consist of asphalt, concrete slabs, jointed stone or riprap, materials can lift, crack, and lose their protective function and especially sealing functions (Figure 1). The roots easily colonize the joints and degrade them; they can be the cause of cracks widening, invasion and the clogging of drains.



Figure 1. On going destruction of a retaining stone and masonery rip rap by a poplar cut several times. When trees are cut many times, their root system in growing faster and stronger, resulting on heavy degradations, like here with uprising of concrete joint.

\section{Method: Management Practices Analyze}

\subsection{General Management Recommendations}

When confronted with these issues, it is recommended not to let the woody vegetation grow on the structures. The presence of herbaceous vegetation is allowed, it maintains soil and protects against surface erosion. However, in order to reconcile landscape and ecological issues with security issues, the presence of trees can be tolerated as long as a certain distance is maintained from the structure foot generally set at $5 \mathrm{~m}$. However, it is advisable to carry out a specific risk study for each structure.

Tree cutting cannot be considered a long-term solution for species able to germinate at the base of the trunk. Indeed, cutting trees acts to strengthen the root system and induces the development of sprouts and suckers that increase the state of degradation of the structure.

As a result, the issue of young woody shoots development in rigid protective coatings is a real one. The ban on the use of phytopharmaceutical products and the amplification of the observed degradations in the case of cutting of trees leave managers facing this complex problem without solution.

\subsection{Wrong Management Practices}

The maintenance of vegetation is essential to ensure the good condition and monitoring of hydraulic structures; it allows the control of the development of woody vegetation which induces structure's premature aging. Non-intervention over several decades has led to a critical state of vegetation on the structures, making them non inspectable and impractical. This densification of the woodlands has led to the installation of burrowing animals, which are also dangerous because their tunnels represent a threat just like the roots of very old trees., sometimes decaying.

Following this awareness, managers first reaction was to start radical cuts; however, clearcutting is the worst solution for embankment works, both from a safety and ecological point of view.

In fact, the felling of large trees induces root decomposition phenomena and massive destruction of habitats. Clearcutting also leads to the expansion of invasive alien species, whose sudden access to light greatly accelerates development. Moreover, mechanical devices also spread these invasive species when their deployment is not controlled.

In the case of trees growing in protective coatings, the cutting of these subjects is usually carried out as a first-effort. The result is, at this time only, visual (apart from allowing to regain hydraulic capacity) and short-term. Indeed, this cut aggravates the problem with the appearance of rejects and suckers which increases the colonized surfaces and the degradations (Figure 2).

Cutting young trees reinforces their root system and induces new shoots development which bring reserves to the stump which thus continues its growth.

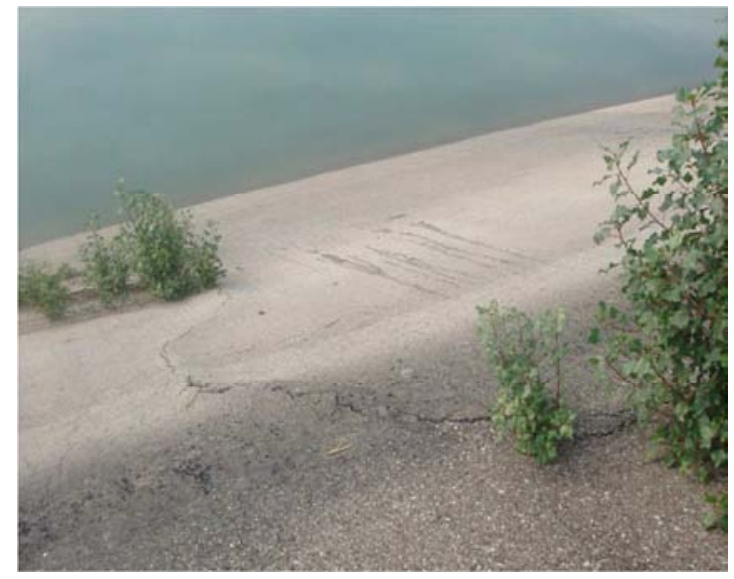

Figure 2. Apparition of numerous root suckers along a fissure on protective tar coating, generated by a shallow root resulting from the slaughtering of the main tree.

\subsection{Complex Conciliation Between Environmental Issues and Vegetation Management}

The complexity lies in the integration of anthropic and environmental issues. It is a matter of reconciling these two issues that are strongly antagonistic from a societal and political point of view: on the one hand the absolute control of the risks, the will to reduce the hazard, to protect human and economic stakes $[\mathrm{PI}]$; on the other hand, the wish to give free rein to rivers, to allow environments renaturation and ecosystems and to encourage biodiversity [GEMA]. 
From a technical point of view, the reconciliation of these issues is also very complex. For example, faced with risk of flooding, watercourse managers are thus obliged to adopt a vegetation maintenance policy implemented on their banks and protective structures while reducing the impact on environment ecological continuity. It is in this context that vegetation management plans are set up to sectorize interventions and minimize the impact on the environment.

Deadlock points and main obstacles to the reconciliation of vegetation maintenance and flood prevention issue

Many studies have highlighted the beneficial effect of woody vegetation on soil supporting and banks strengthening. However, even though these benefits may exist temporarily on protection works or their immediate contact, a negative effect can be demonstrated as this same vegetation is likely to create damage and destabilize [7].

Important development of vegetation on the hydraulic structures affects the effectiveness of visual inspection, ensuring good maintenance and disorders and prevention of breaches 1 . Structures invaded by vegetation also have the disadvantage of being attractive places for macrofauna species, generating holes which are gateways to water and these burrows increase the risk of breakage.

Trees root systems, in many cases, dismantle the constituent materials of the hydraulic structure and cause risks of internal erosion. Woody vegetation is also a source of external erosion; an uprooted tree, with its root system, a large amount of materials. It creates a breakdown of the embankment or of a low point on the ridge which could induce the overflow.

In the event of flooding of the embankments, the action of vortex eddies can accentuate this erosion. In addition to external factors like wind or snow, several causes can be the source of a fallen tree: the root structure, its slope steepness, ageing and disease. It is therefore important to perform indepth diagnostics of vegetation located on hydraulic structures in order to limit any risk of erosion or breakage [1].

Log jams generated by dead wood or whole trees lead to two types of risk: one is overflow by accumulation and loading (bridge, water intake,...) during flooding, the other one is destruction by drift wood hitting infrastructures.

Regular management of woodlands and elimination of hazard trees with a risk of falling and carrying over should be performed, particularly in urban areas. The various factors listed above show that vegetation cannot be left without management in areas where the "PI" issue is major matter.

\section{Results: From Conciliation to Innovation}

\subsection{A Still too Often Dichotomous View}

Certain old works have not been maintained any more for

\footnotetext{
${ }^{1}$ Decree No. 2015-526 of 12 May 2015, related to the rules applicable to hydraulic structures built or developed to prevent floods and to the safety rules, which defines their supervision and maintenance modalities.
}

several decades. They constitute preserved zones but are not functional anymore and present a probability of very important failure (Figure 3).

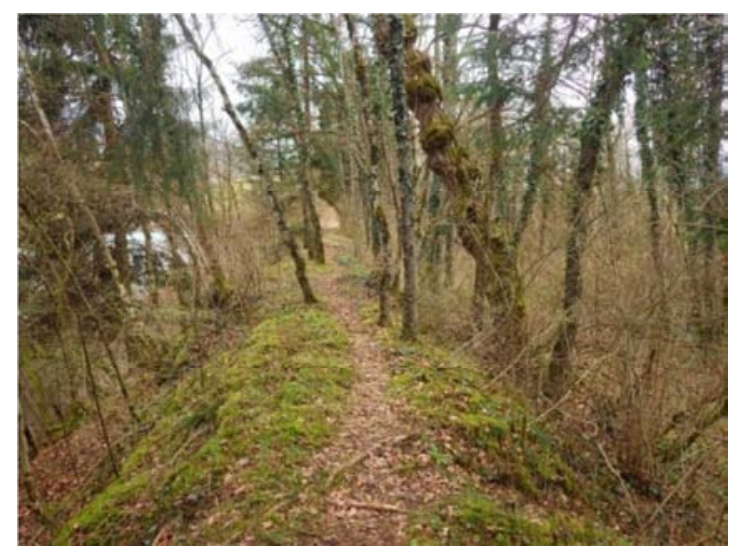

Figure 3. Entirely wooded dam presenting a critical condition in respect of the safety of the work. Trees are implanted on the both sides of the dike; most of them are dangerous in case of uprooting.

Conversely, many works of protection against floods were conceived or are managed in a very drastic way, whether entirely "concreted" or "tarred" (Figure 4), and where the chemical means were before largely used for the eradication of the woody plants.

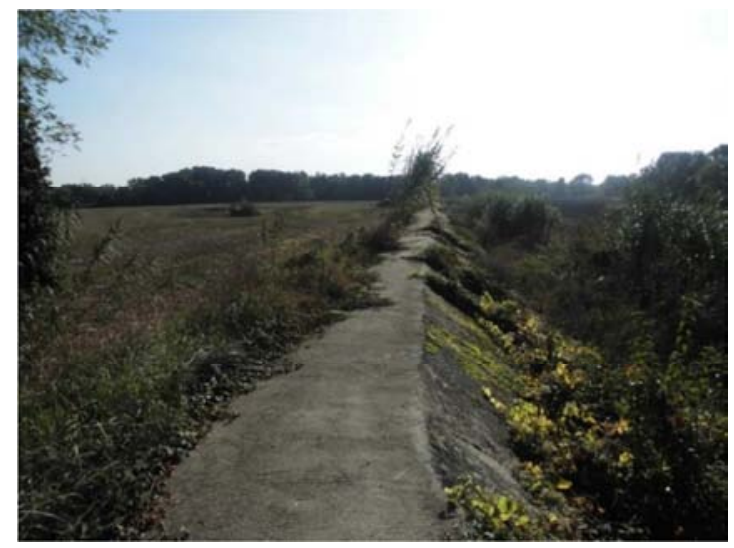

Figure 4. Entirely concreted dike where the invading species still manage to grow and deteriorate the concrete.

They are detrimental to the functioning of the ecosystem, creating very important interruptions of the green corridors and going against the concept of integration of GEMA and PI.

This situation is equally encountered in slightly urbanized zones, where challenges PI are minors. Husbandries tend to make the riparian vegetation disappear; from large alluvial forests, there remains only a few meters width grassy buffer area in edge of rivers.

\subsection{Toward a Controlled Conciliation of Vegetation and Flood Prevention Issues}

Vegetation of banks and protective structures using plant techniques brings unquestionable ecological and landscape benefits. 
When plant techniques alone are not enough to protect the banks (though they may be preferable), vegetated rip raps offer a very interesting alternative (Figure 5).

These techniques need to be encouraged for watercourse enhancement projects. Riparian vegetation plays an essential role in the regulation of watercourses from flooding impacts.

Riparian vegetation is a huge energy dissipator. It is very effective particularly in the areas of flood expansion. The maintenance of riparian vegetation is therefore necessary in upstream areas where the stakes in terms of PI are often lower [8].

Riparian vegetation has many other features and its interactions with the environment are multiple. It helps to control soil erosion, acts as an adsorption and degradation filter of pollution that migrate from the terrestrial to the aquatic environment.

It is an essential interface that is home to a great wealth of species. Riparian vegetation constitutes an ecological corridor that allows exchanges between populations, and it is sometimes the last wooded corridors in heavily anthropized areas. It also plays the role of providing shade and nutrient supply for small streams. Finally, it plays a social role, particularly through its recreational and landscaping functions.

However, there is a contradiction between the will to vegetate the banks and the desire to avoid the development of woody vegetation on dikes. Restrictions are needed when the bank that must be defended is extended by a flood defense structure on the embankment from which grass is the only type of vegetation that is tolerated and recommended.

The conciliation of civil and ecological engineering is therefore possible. In that respect, it has been proposed to allow woody vegetation to develop in banks when the top of bank is more than 5 meters away from the foot of the river bank [1].

This measure is a good example of reconciling IP and GEMA issues in which a compromise can be established between protection against floods and maintenance of functional biodiversity (Figure 5). However, often the use of plant techniques or spontaneous revegetation is not considered and this for several possible reasons: technical constraints, economic, land or maintenance strategy works.



Figure 5. Illustration of the good reconciliation of the GEMA and PI issues. a bank protected by plant techniques and a dike kept in grass favoring the diversity of environments.

\subsection{From Ancestral to Innovative Solutions}

\subsubsection{Ancestral Methods}

In order to provide an economic and ecological solution, eco-grazing, which involves grazing animals (sheep, goats or cattle), conserves natural areas and helps to preserve biodiversity (Figure 6). This ancestral method aims to keep environments open by preventing brush and shrubs from colonizing the space. Eco-grazing limits the use of mechanical devices and avoids the use of chemicals.



Figure 6. Return to ancestral methods in order to avoid the use of chemicals products.

\subsubsection{Innovative Solutions}

Since the use of chemicals near watercourses has been banned since 2006 and where no other effective solutions exist on the market, alternative methods are under study. A solution, respectful of the environment and of the regulations, needs to be found to devitalize the trees threatening hydraulic structures. New alternative solutions patented have recently been developed to eradicate young woodlots growing in stone masonry which have the effect of degrading the waterproofing of wall facings [9].

New solutions based on the physiology of trees are in research and development with some new solutions for which a patent is pending (Figure 7). These new methods allow young tree devitalization that respect the environment and does not damage hydraulic structures. Reparations are thus largely minimized.

Hazardous woody treatment solutions are fully integrated into the new management trends brought by GEMAPI.

The implementation of sustainable and environmentally responsible solutions has become indispensable. Since 2006, the implementation of restrictions on the use of phytopharmaceuticals near any water point has resulted in the establishment of an untreated zone (ZNT). This ZNT is 5 meters wide from the edge of the stream and can extends up to 100 meters depending on the product used.

The phytocide products allowing the devitalization of strains are based on active molecules such as fluroxypyr and triclopyr - highly toxic for aquatic organisms; they have a ZNT of more than $5 \mathrm{~m}$, rendering them unusable in almost all cases.

In addition, in the context of Sustainable Development and in order to follow European directives, new laws and the 
Ecophyto Plan in particular, aim to significantly reduce the use of chemicals because of their very negative effects [10] et [11].

Many managers have already committed to restrict the use of plant protection products but are faced with the lack of an effective alternative.

In response to these issues, ARBEAUSOLutions has launched a research and development program aimed at providing managers with alternative technical solutions to eradicate woody vegetation that can cause risks for hydraulic structures. The notion of low environmental impact is at the heart of the development of these innovative solutions

These new solutions for the control of young woody species growing on structures are based on the disruption of the good metabolic functioning of the tree, notably by disturbing the flow of sap from the roots, essential for of the aerial part development and for the constitution of reserves and ensuring the durability of the tree (Figure 7).



Figure 7. Innovative solutions for vegetation control are implemented by ARBEAUSOLutions on canal dikes.

Part of these methods are based on the optimization of existing techniques used in forestry management. Debarking wood is a method used in the forestry environment to thin afforestation and promote the development of certain target trees by causing decay of the one economically less profitable for afforestation. Debarking is also a recognized method in the field of management of invasive woody species and gives interesting results. Applied alone, the negundo maple girdling has a success rate of $65 \%$, which is still low compared to chemical devitalization techniques using phytocides that devitalize the standing tree This success rate also depends on the type of woody species. It is less than $60 \%$ on poplars. One of the solutions patented by ARBEAUSOLutions achieves a $90 \%$ success rate by combining girdling with other biochemical and/or thermal techniques $(70 \%$ devitalized subjects in Phase 1 and $95 \%$ after Phase 2 on a total of 80 subjects treated (Figure 8 ).

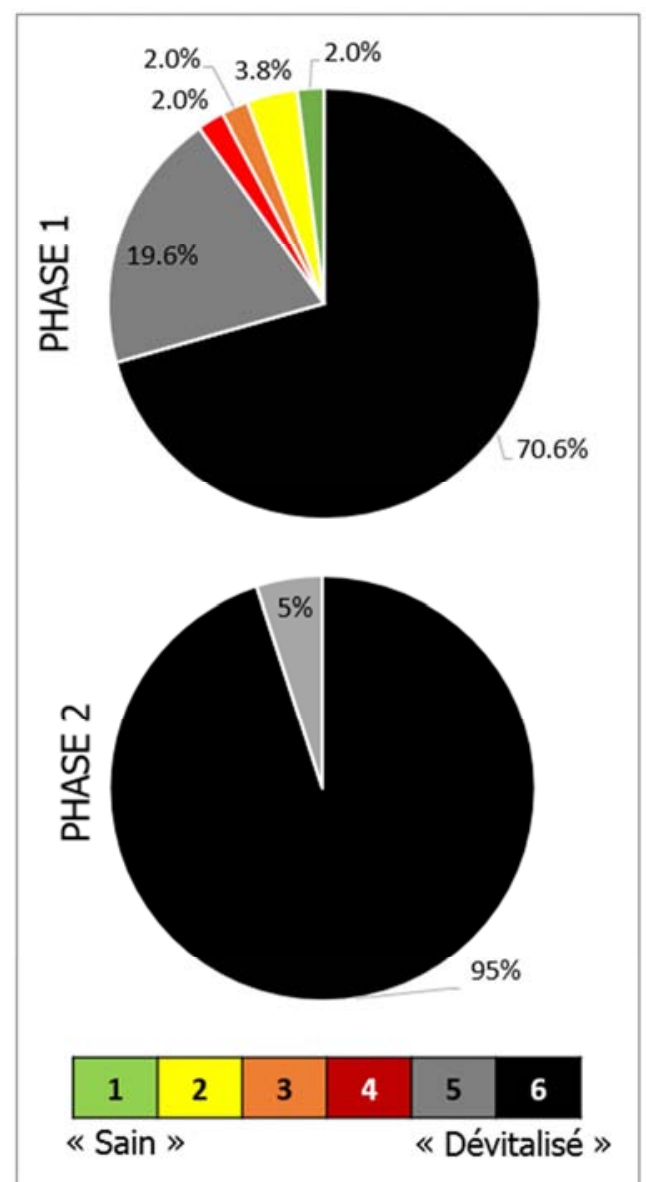

Figure 8. Results of devitalization of poplars by innovative processes in 2 phases developed by ARBEAUSOLutions. the second phase results are observed at the next spring, one year after the first experimentation.

One of the preferred solutions is the application, on the debarked part of the tree, of a process preventing the healing of plant tissues. The impact of this process on the surrounding environment has been evaluated and the results confirm a very low ecological impact. The on-site test campaigns of the process give very encouraging results on the poplar (Figure 9 and Figure 10), which is a highly developed species on the hydraulic structures.

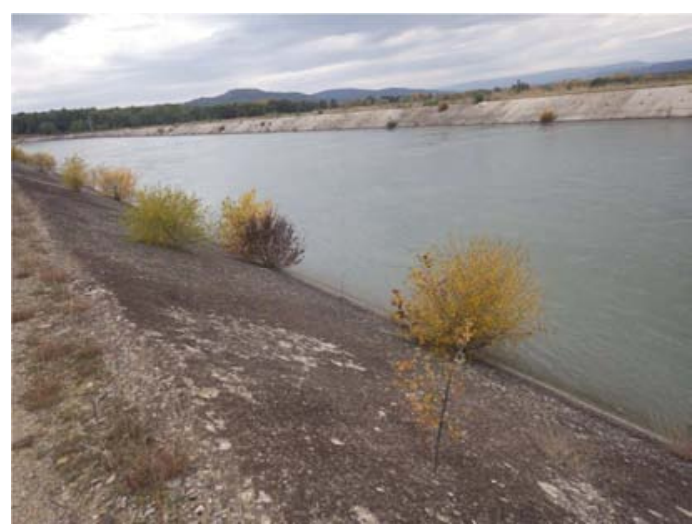

Figure 9. Colonization of concrete lock walls by young poplars which are present in drainage system breaks. 


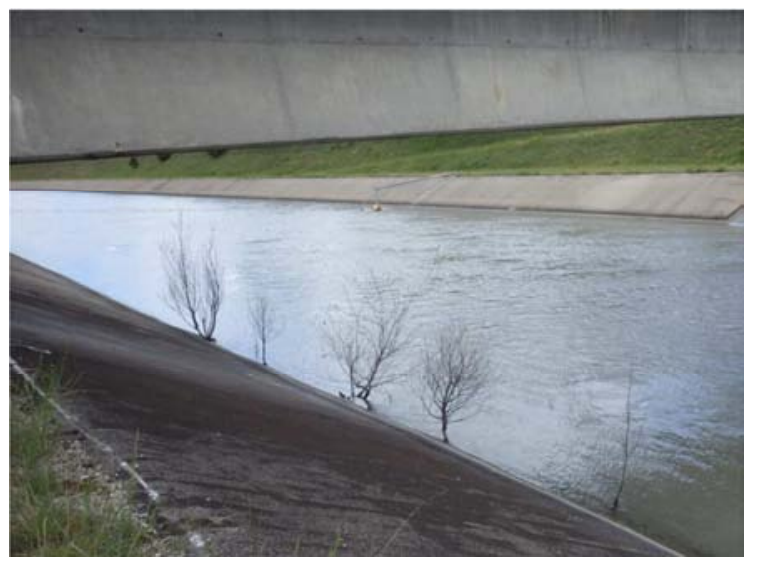

Figure 10. Devitalized poplars through innovative ARBEAUSOLutions processes; research conducted for 5 years in INRA lab, green houses and on work sites.

Girdling combined with a lowering of the localized temperature also gives good results. The tests were also conducted on robinias pseudo-acacias, willows, ash trees, oak trees as well as heaven trees and plane trees, although these species are more rarely responsible for a dense masonry colonization. The results on these latter species, although encouraging, are not presented here because the samples are insufficient for carrying out robust statistical tests.

However, on paved, bituminous or stone-surfaced structures, tree vegetation is exclusively implanted in cracks and degraded joints. Tree devitalization must therefore be accompanied by a repair of the coating in order to prevent any new implantation.

These repairs must be carried out when the tree is completely devitalized; indeed, if live parts of tree remain at the strain level, the regeneration of the plant tissues is such that repaired zones degradations occur quickly.

However, these methods are still long to implement, processes automation are being developed to allow the industrialization of techniques.

At present, it takes a day for 2 operators to treat a dozen trees. The speed of intervention strongly depends on the morphology of the trees and their diameter. Numerous sprigs are much longer and more complex to treat than standard trees with a single trunk.

Coppicing, commonly practiced by hydraulic structures managers, therefore has significant disadvantages because, in addition to increasing the root volume, it generates the development of many strands which increases the processing time, or even makes it sometimes impossible to implement.

The tools used to perform girdling are mostly manual. We find the tools used in forestry such as planes, debarker tools (shovel to bark) or tree girdling tools.

Some semi-automated tools exist but are not always adapted to the girdling of young trees on site; tools such as chainsaw-log debarkers have been designed to remove the bark once the tree is cut down and cannot be used in their prior condition.

Although the results of these first alternative methods are conclusive, they cannot compete with the chemical methods, widely used in the past, in terms of speed of action and implementation as well as cost.

For large trees located on hydraulic structures the only effective way is the mechanical grubbing which is destructive for the works and expensive to implement.

It is therefore necessary to practice regular maintenance of the structures and to carry out preventive interventions to avoid the evolution towards this type of configuration.

\section{Discussion and Conclusion}

There is no need to distinguish flood protection and management of aquatic environments. The proper functioning of ecosystems - as a key condition to the quality of environment - contributes to the healthy functioning and the quality of life of inhabited places, these same places which concentrate the infrastructures of protection against floods and which are too often shown as incompatible with the maintenance of vegetation.

New solutions must therefore emerge to remove this still stubborn opposition. Plant engineering techniques, experiencing a boom, can contribute to this and management choices will have to be adapted accordingly. PI often echoes the establishment of protective works; however, it is recognized that this is not the only way we can organize the protection of property and people (dike retreat, creation of retention ponds, and even displacement of issues outside the flood zone). Changes in the culture of flood risk and floods control and adaptation of urbanization in the flood zone would allow better reconciliation between the two aspects GEMA and PI carried by the GEMAPI that we would like to be inseparable.

So, management methods and the vision for maintaining hydraulic structures would have to evolve. In many cases the structures have been constructed without taking into account the fact that nature is irrevocably seeking to regain its rights and that the fight against the development of vegetation would be recurrent.

Ancestral practices were based on permanent harvesting of small woody plants and brushing by flocks. Grazing, which is difficult to implement in modern societies, is an effective means of maintaining open environments; widely used in ecological restoration, it is possible to extend it on hydraulic structures embankment, but it is not however adapted to the walls of canals and masonry or concreted works. These coatings, which guarantee the functionality of the structures, require rigor and perseverance from the structure managers.

The innovative solutions for dangerous trees devitalization presented above enable to provide a response to current problems.

Managing the development of riparian vegetation in order to maintain its positive effects on the environment (shading, water pollution, bank stabilization, biodiversity) while limiting the negative impacts that vegetation might create is essential. The reconciliation of these functions involves the implementation of management plans that prioritize actions, spread them over time, define specific measures and 
protocols, and thus minimize the impact on the riparian environment.

\section{References}

[1] Vennetier, M, Zanetti C, Mériaux P, (2015). Gestion de la végétation des ouvrages hydrauliques en remblai, Cardère éditeur, Irstea Aix en Pce, p. 232.

[2] Evette, A, Zanetti C, Cavaillé P, Dommanget F, Mériaux P et Vennetier M (2014) La gestion paradoxale des ripisylves des cours d'eau de piedmont alpin endigués, gestion sécuritaire ou promotion de la biodiversité, Journal of Alpine Research | Revue de géographie alpine, 102-4.

[3] Picon, P., Desagher, V., (2017). Mise en œuvre de la GEMAPI une première expérience à partager, SMAVD, Novembre 2017, p. 27.

[4] Zanetti C., Macia J., Liency N., Vennetier M., Mériaux P., Provansal M., (2016). Roles of the riparian vegetation: the antagonism between flooding risk and the protection of environments, 3rd European Conference on Flood Risk Management, Lyon, 17-21th November.

[5] Foussadier R, (2003), Les forêts riveraines des cours d'eau, écologie, fonctions et gestion, Edition IDF p124.
[6] Piégay H., Pautou G., Ruffinoni C. (2003). Les forêts riveraines des cours d'eau: écologie, fonctions et gestions, Institut pour le Développement Forestier, 465p.

[7] Zanetti, C, (2010). Caractérisation du développement des systèmes racinaires ligneux dans les digues. Thèse de Doctorat. Université de Provence - IRSTEA Aix-en-Provence, p. 297.

[8] Evette, A., P. -A. Frossard, N. Valé, S. Leblois \& A. Recking, (2017). Oser le génie végétal en rivière de montagne - Retour d'expérience sur les ouvrages Géni'Alp. Sciences Eaux \& Territoires Hors-série.

[9] Macia J., (2018). Identification et essais de techniques de dévitalisation des essences ligneuses générant des risques sur les ouvrages hydrauliques, Thèse de Doctorat (confidentielle). Financement CIFRE - ARBEAUSOLutions. Université d'Avignon et des Pays du Vaucluse - INRA UR407 Avignon.

[10] Perkins, PJ., Boermans HJ., Stephenson GR., (2000). Toxicity of glyphosate and triclopyr using frog embryo teratogenesis assay - xenopus. Environmental Toxicology and Chemistry, Vol. 19, No. 4, pp. 940-945.

[11] Petty DG., Getsinger KD., Woodburn KB., (2003). A Review of the Aquatic Environmental fate of Triclopyr and its Major Metabolites, J. Aquat. J. Aquat. Plant Manage., 41: 69-75. 